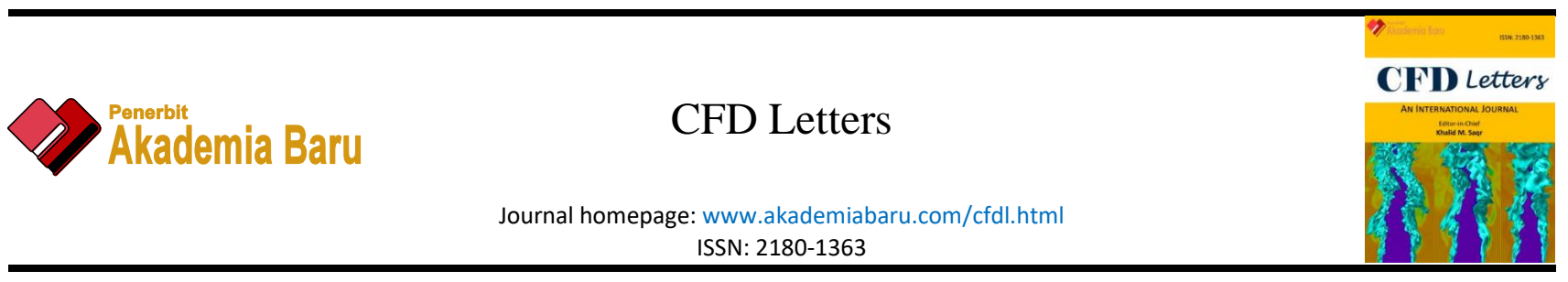

\title{
Numerical Study of Wind-Tunnel Wall Effects on Lift and Drag Characteristics of NACA 0012 Airfoil
}

\author{
Mostafa Abobaker ${ }^{1}$, Abdulhafid M. Elfaghi ${ }^{2,}{ }^{*}$, Sogair Addeep ${ }^{1}$ \\ Department of Aeronautical Engineering, Faculty of Engineering, University of Zawia, Libya \\ Faculty of Mechanical and Manufacturing Engineering, Universiti Tun Hussein Onn Malaysia, 86400 Parit Raja, Malaysia
}

\section{ARTICLE INFO}

\section{Article history:}

Received 23 September 2020

Received in revised form 21 November 2020

Accepted 25 November 2020

Available online 30 November 2020

\section{Keywords:}

Computational fluid dynamics (CFD);

airfoil; wall effect; lift; drag; turbulence

model; lift curve slope; wall correction;

domain height

\section{ABSTRACT}

\begin{abstract}
Possible interference effects of the wind tunnel walls play an important role especially for measurements in closed-wall test sections. In this study, a numerical analysis of two-dimensional subsonic flow over a NACA 0012 airfoil at different computational domain heights, angles of attack from $0^{\circ}$ to $10^{\circ}$, and operating Reynolds number of $6 \times 10^{6}$ is presented. The work highlights the role of computational fluid dynamics (CFD) in the investigation of wind tunnel wall effect on lift curve slope correction factor $\left(K_{a}\right)$. The flow solution is obtained using Ansys Fluent software by solving the steady-state continuity and momentum governing equations combined with turbulence model $k-\omega$ shear stress transport (SST-KW). The numerical results are validated by comparing with the available experimental measurements. Calculations show that the lift curve slope correction results are very close to the published data.
\end{abstract}

Copyright @ 2020 PENERBIT AKADEMIA BARU - All rights reserved

\section{Introduction}

When simulating the flow over an airfoil inside wind tunnel, the effect of the tunnel walls to the flow plays an important role in determining the flow features and in quantifying the airfoil performance such as lift and drag coefficients. Currently, the estimation of the effects of the tunnel walls on the flow around a model relies only on numerical methods. CFD is one of the numerical methods of choice in the simulation and design of many aerospace, automotive and industrial components and processes in which fluid or gas flows play a major role.

Wall interference has a major impact on the performance of the wind tunnel. CFD has been used extensively in recent years to investigate transonic wall interference. In order to reduce the blockage effect, shock wave reflection, etc., a transonic wind tunnel typically has porous or slotted walls on the test section. The wind tunnel flow field is greatly affected by the permeable wall, and it must thus

\footnotetext{
* Corresponding author.

E-mail address: abdulhafid@uthm.edu.my (Abdulhafid M Elfaghi)
} 
be properly modelled [1]. A variety of researchers have applied the principle of blockage correction to wind tunnel test results. The correction method proposed by Pope and Harper [2] was used by Blackwell et al., [3] to correct the effects of the blockage on wind speed and pressure to evaluate the output efficiency of a Savonius wind turbine. In the analysis, while the uncertainty in the correction factor of the Pope and Harper was calculated at 50\%, the approach was applied because there was no other tool at the time to correct the blocking effect for the Savonius wind turbine. Alexander et al., [4] proposed a minor modification to the Savonius turbine by Maskell's process [5]. They calculated a Savonius turbine's drag force, and then presented the correction factor as updated. Ross and Altman [6] investigated the wake characteristics and output generated at different physical scales and in two different wind tunnels by the same Savonius vertical-axis wind turbine. By conducting a wind tunnel test using a small horizontal-axis wind turbine. Chen et al., [7] confirmed that the blockage effect was more affected by the tip speed ratio (TSR), blade pitch angle, and blockage ratio, and less affected by the wind speed.

Numerical simulations of the flow around a three-bladed model-scale wind turbine with horizontal axis were reported by Zaghi et al., [8]. In all test cases, the turbine diameter is comparable with test section dimensions, and the blockage effects were significant. Two circular wind tunnels were tested. For the first, the radius was chosen to retain the same cross section as the actual wind tunnel while in the second, it was set to be equal to half of the smallest cross-section dimension. The aerodynamic performances of the turbine, in terms of power and thrust coefficients, were analyzed and compared with available experimental data.

Owing to the possibility of unstable or structural failure, nonlinear anomalies of an airfoil/wing have created great interest. Three of the most common causes of nonlinearity are high angle of attack, transonic flow, and elastic structure [9-12]. Two-dimensional wind tunnel experiments were conducted to investigate the buffeting flow over a static airfoil and an oscillating pitching airfoil [1314]. However, if the distance between the wind tunnel walls is not sufficiently wide relative to the characteristic length of the object being studied, the wall effects cannot be ignored, because they can greatly affect the object's aerodynamic characteristics. Malavasi and Blois [15] made use of a 2D PIV technique to calculate the flow structure around an elongated rectangular cylinder near a solid wall. The time-averaged flow patterns illustrate the significant distortions due to the solid surface. Ota et al., [16] suggested a two-dimensional wall effect correction function for the mean forces, as well as the fluctuating forces and the number of Strouhals. Ota's formula was used to correct Chen and Fang's Strouhal number for an inclined flat plate [17]. A correction factor of 1.21 has been adopted based on Ota's formula for correction and the least-square test. To yield one common value, the Strouhal numbers calculated with different blockage ratios have been corrected.

Zhou et al., [18] studied the wall effects at a high angle of attack on a NACA 0012 airfoil. It was presumed that the flow through the airfoil is fully separated. The effects on both a static airfoil and an oscillating airfoil were investigated at Reynolds number varies from $10^{5}$ to $3 \times 10^{5}$. A new formula for wall correction has been determined for the Strouhal number. The results show that for an oscillating airfoil, a combination of the excitation frequency and the amplitude of the oscillating airfoil defines the lock-in. The lock-in region decreases as the blockage ratio increases. They also found the Reynolds number has a minor effect on the region of lock-in, both in unconfined flow and confined flow.

Abdul Hakim et al., [19] carried out a low-speed wind tunnel analysis on the 2D airfoil model in the range from $0^{\circ}$ to $35^{\circ}$ angle of attack at $1.0 \times 10^{6}, 1.5 \times 10^{6}$ and $2.0 \times 10^{6}$ Reynolds. It is concluded that the number of Reynolds $1.0 \times 10^{6}$ was separated at $16^{\circ}$; and as the number of Reynolds was increased; the separation of the flow was delayed. For Reynolds number $1.5 \times 10^{6}$ at $18^{\circ}$ and Reynolds number $2.0 \times 10^{6}$ at $20^{\circ}$, the flow was totally separated. 
In the available numerical wind tunnel wall interference studies, angle of attach is usually achieved by changing the flow direction while keeping airfoil and the mish inside the domain unchanged which do not representing the real wind tunnel flow where the flow is parallel to the wall. Hence, in the current study, unstructured grid for each angle of attack is generated where the flow is kept parallel to the domain the airfoil is tilted by angle of attack. The height of tunnel wall varies from 2-chord to 7-chord of the airfoil. The angle of attack of the airfoil varies from $0^{\circ}$ to $10^{\circ}$, and the Reynolds number is $6 \times 10^{6}$. The goal of this paper is to explore the wall effects on lift and drag coefficients for NACA 0012 airfoil at different angles of attack and to provide better understanding of wall interference effects for the airfoil.

\section{Numerical Setup}

The Reynolds-averaged Navier-Stokes equations are obtained by adding a perturbation to the average values of the flow variables in the Navier-Stokes equations. The continuity and momentum equations are straightforward. When this procedure is applied to the energy equation, a conservation equation for the total energy including the turbulent kinetic energy is produced [20-21]. A conservation equation for the total energy of the mean flow can then be obtained by subtracting out the equation for the turbulent kinetic energy. The result is the Reynolds-averaged Navier -Stokes equations in the form $[17,22]$.

$\frac{\partial \bar{\rho}}{\partial t}+\frac{\partial \bar{\rho} \widetilde{u}_{j}}{\partial x_{j}}=0$

$\frac{\partial \bar{\rho} \widetilde{u}_{i}}{\partial t}+\frac{\partial \bar{\rho} \widetilde{u}_{i} \widetilde{u}_{j}}{\partial x_{j}}+\frac{\partial \bar{p}}{\partial x_{i}}=\frac{\partial}{\partial x_{j}}\left(\bar{\tau}_{i j}-\overline{\rho u_{\imath}^{\prime} u_{\jmath}^{\prime}}\right)$

$\frac{\partial \bar{\rho} \hat{E}}{\partial t}+\frac{\partial \bar{\rho} \hat{H} \tilde{u}_{j}}{\partial x_{j}}=\frac{\partial}{\partial x_{j}}\left(\tilde{u}_{i}\left(\bar{\tau}_{i j}-\overline{\rho u_{\imath}^{\prime} u_{j}^{\prime}}\right)\right)-\frac{\partial}{\partial x_{j}}\left(\bar{q}_{j}+\overline{\rho h^{\prime} u_{\jmath}^{\prime}}\right)$

$\bar{\tau}_{i j}=\mu\left(\frac{\partial \widetilde{u}_{i}}{\partial x_{j}}+\frac{\partial \widetilde{u}_{j}}{\partial x_{i}}-\frac{2}{3} \frac{\partial \bar{u}_{k}}{\partial x_{k}} \delta_{i j}\right)$

where the first index indicates the plane along which the stress acts, and the second gives the coordinate direction.

$\bar{q}_{j}=-k \frac{\partial \bar{T}}{\partial x_{j}}$

In the energy equation, the total energy and enthalpy of the mean flow are given by:

$$
\begin{aligned}
& \widehat{E}=\tilde{e}+\frac{1}{2} \tilde{u}_{k} \tilde{u}_{k} \\
& \widehat{H}=\tilde{h}+\frac{1}{2} \tilde{u}_{k} \tilde{u}_{k}
\end{aligned}
$$

Notice that as a consequence of the averaging procedure, two new unknowns have been introduced: $\tau_{i j=-} \rho u_{i}^{\prime} u_{j}^{\prime}$, which is an apparent stress due to turbulent fluctuation, is known as Reynolds stress, and $\overline{\rho h^{\prime} u_{j}^{\prime}}$ which is an apparent heat flux due to the turbulent fluctuations, is known 
as the Reynolds heat flux. While it is possible to derive transport equations for these second-order correlations, these equations will involve third-order correlations. This process can be continued indefinitely. At some point, the correlations must be modeled based on empirical information. The fact that the system cannot be solved without relating these correlations to the mean flow variables (or lower-order correlations) is known as the closure problem. This is done through a turbulence model. In the lowest-order approximation due to Boussinesq, the Reynolds stresses are related to the mean flow gradients by:

$-\overline{\rho u_{\imath}^{\prime} u_{\jmath}^{\prime}}=\mu_{t}\left(\frac{\partial \bar{u}_{i}}{\partial x_{j}}+\frac{\partial \bar{u}_{j}}{\partial x_{i}}-\frac{2}{3} \frac{\partial \bar{u}_{k}}{\partial x_{k}} \delta_{i j}\right)-\frac{2}{3} \bar{\rho} k \delta_{i j}$

where $\mu_{t}$ is the eddy viscosity and $k$ is the turbulent kinetic energy given by

$k=\frac{\overline{\rho_{\frac{1}{2}} u_{k}^{\prime} u_{k}^{\prime}}}{\bar{\rho}}$

Similarly, the Reynolds heat flux can be related to the mean temperature gradient by:

$\overline{\rho h^{\prime} u_{\jmath}^{\prime}}=-k_{t} \frac{\partial \bar{T}}{\partial x_{j}}$

Where, $k_{t}$ is the eddy thermal conductivity. With these relations, the Reynolds-averaged NavierStokes equations take the form

$\frac{\partial \bar{\rho}}{\partial t}+\frac{\partial \bar{\rho} \widetilde{u}_{j}}{\partial x_{j}}=0$

$\frac{\partial \bar{\rho} \widetilde{u}_{i}}{\partial t}+\frac{\partial \bar{\rho} \widetilde{u}_{i} \widetilde{u}_{j}}{\partial x_{j}}+\frac{\partial \bar{p}}{\partial x_{i}}=\frac{\partial \bar{\tau}_{i j}^{T}}{\partial x_{j}}$

$\frac{\partial \bar{\rho} \hat{E}}{\partial t}+\frac{\partial \bar{\rho} \widehat{H} \widetilde{u}_{j}}{\partial x_{j}}=\frac{\widetilde{u}_{i} \bar{\tau}_{i j}^{T}}{\partial x_{j}}-\frac{\partial \bar{q}_{j}^{T}}{\partial x_{j}}$

where the total stress tensor and heat flux are

$$
\begin{aligned}
& \bar{\tau}_{i j}^{T}=\left(\mu+\mu_{t}\right)\left(\frac{\partial \bar{u}_{i}}{\partial x_{j}}+\frac{\partial \bar{u}_{j}}{\partial x_{i}}-\frac{2}{3} \frac{\partial \bar{u}_{k}}{\partial x_{k}} \delta_{i j}\right) \\
& \bar{q}_{j}^{T}=-\left(k+k_{t}\right) \frac{\partial \bar{T}}{\partial x_{j}}=-\gamma\left(\frac{\mu}{P r}+\frac{\mu}{P r_{t}}\right) \frac{\partial \bar{e}}{\partial x_{j}}
\end{aligned}
$$

and the Prandtl number and turbulent Prandtl number are given by

$$
\begin{aligned}
& \operatorname{Pr}=\frac{\mu C_{p}}{k} \\
& P r_{t}=\frac{\mu_{t} C_{p}}{k_{t}}
\end{aligned}
$$


The SST k- $\omega$ turbulence model is a two-equation eddy-viscosity model that is used for many aerodynamic applications. It is a hybrid model combining the Wilcox $k-\omega$ and the $k-\varepsilon$ models. A blending function activates the Wilcox model near the wall and the $k-\varepsilon$ model in the free stream. This ensures that the appropriate model is utilized throughout the flow field. Where $k-\omega$ model is well suited for simulating flow in the viscous sub-layer, while, $k-\varepsilon$ model is ideal for predicting flow behavior in regions away from the wall [23].

\section{The Computational Domain}

In order to study the effect of wind tunnel walls on the lift and drag coefficients of NACA 0012 airfoil a set of CFD analysis cases are performed with different domain heights. The computational domain (wind tunnel) heights are $2 C, 3 \mathrm{C}, 4 \mathrm{C}, 5 \mathrm{C}, 6 \mathrm{C}$, and $7 \mathrm{C}$ where $\mathrm{C}$ is the chord length of the airfoil. In addition to these cases, one reference case with large domain size of $24 \mathrm{C}$ is calculated. The boundary conditions are set as pressure far field for front, upper and lower domain sides. The back side is defined as pressure outlet. The studied range of angles of attack starts from 0 to 10 degrees. It is worth to note that, for every angle of attack the airfoil is tilted by that angle and a new mesh is generated. The reference case models the free stream condition where no wind tunnel walls are present. Lift curve slopes from each case is calculated, and a correction factor is obtained by dividing by free stream lift curve slope.

Simulations for various angles of attack were done from the wind tunnel wall heights and then validate them with existing experimental data. In all cases, a rectangular computational domain is selected with unstructured mesh as illustrated in Figures 1 and 2. Dimensions of the computational domain is $24 \mathrm{C}$ in length and varies from $2 \mathrm{C}$ to $7 \mathrm{C}$ in width.

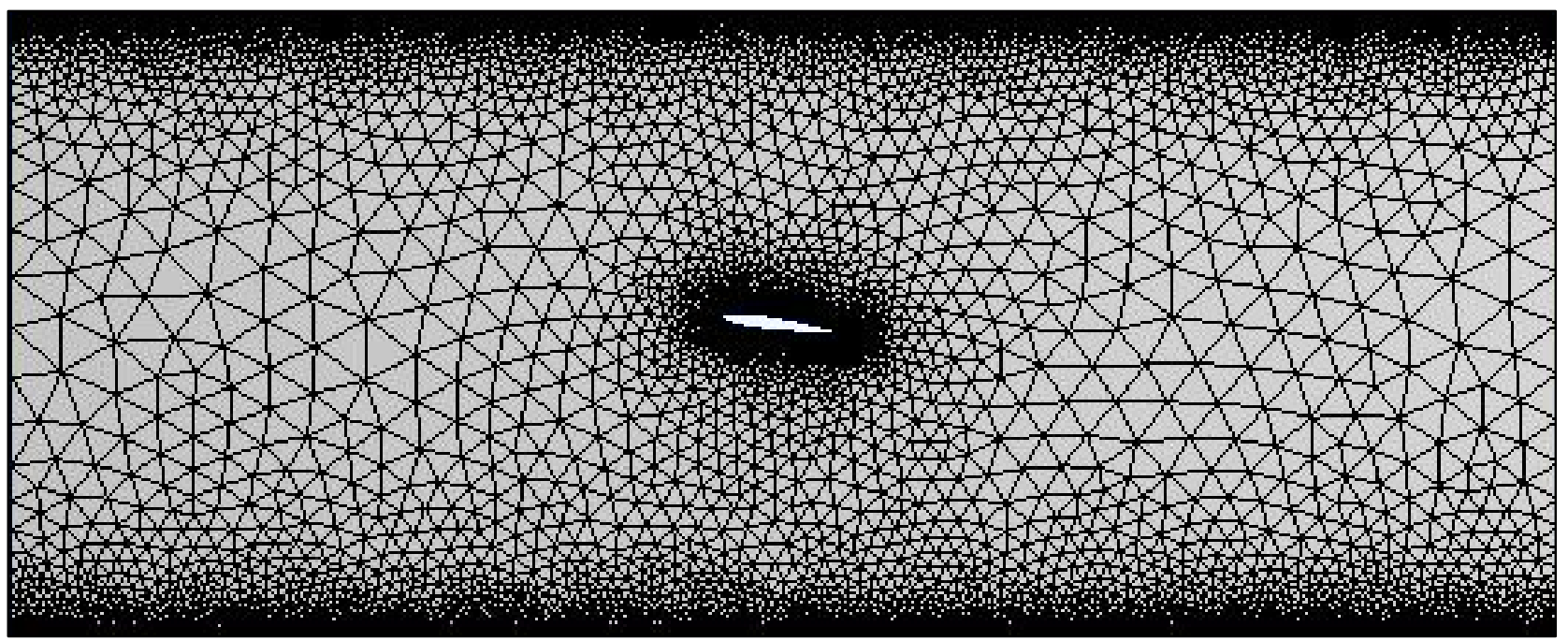

Fig. 1. Unstructured mesh used in wind tunnel wall simulations showing near walls mesh refinement

For unstructured mesh simulation, a mech sensitivity study is performed. As shown in Table 1 and illustrated in Figure 3. The sensitivity of lift and drag coefficients to grid size is studied. It is clear from the table and figure that grid with 12500 nodes gives satisfied results compared with other mesh sizes. 


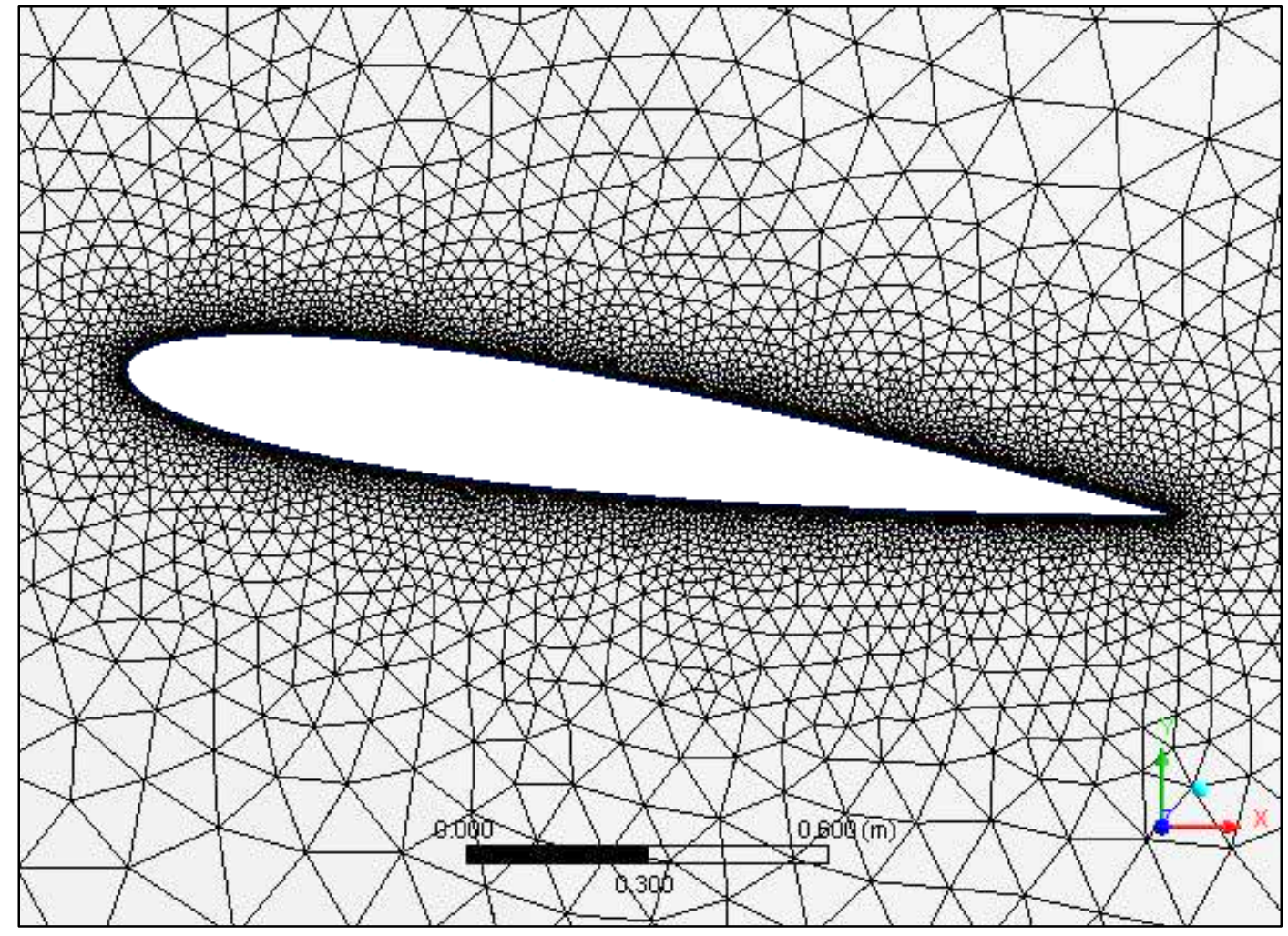

Fig. 2. Refined unstructured grid used around the airfoil surface to simulate boundary layer region

Table 1

Grid independence study

\begin{tabular}{lll}
\hline mesh size & $C_{\mathrm{l}}$ & $\mathrm{C}_{\mathrm{d}}$ \\
\hline 9268 & 0.6 & 0.01175 \\
12500 & 0.648 & 0.01136 \\
14000 & 0.649 & 0.01149 \\
16400 & 0.64966 & 0.01139 \\
30000 & 0.651 & 0.01146 \\
\hline
\end{tabular}

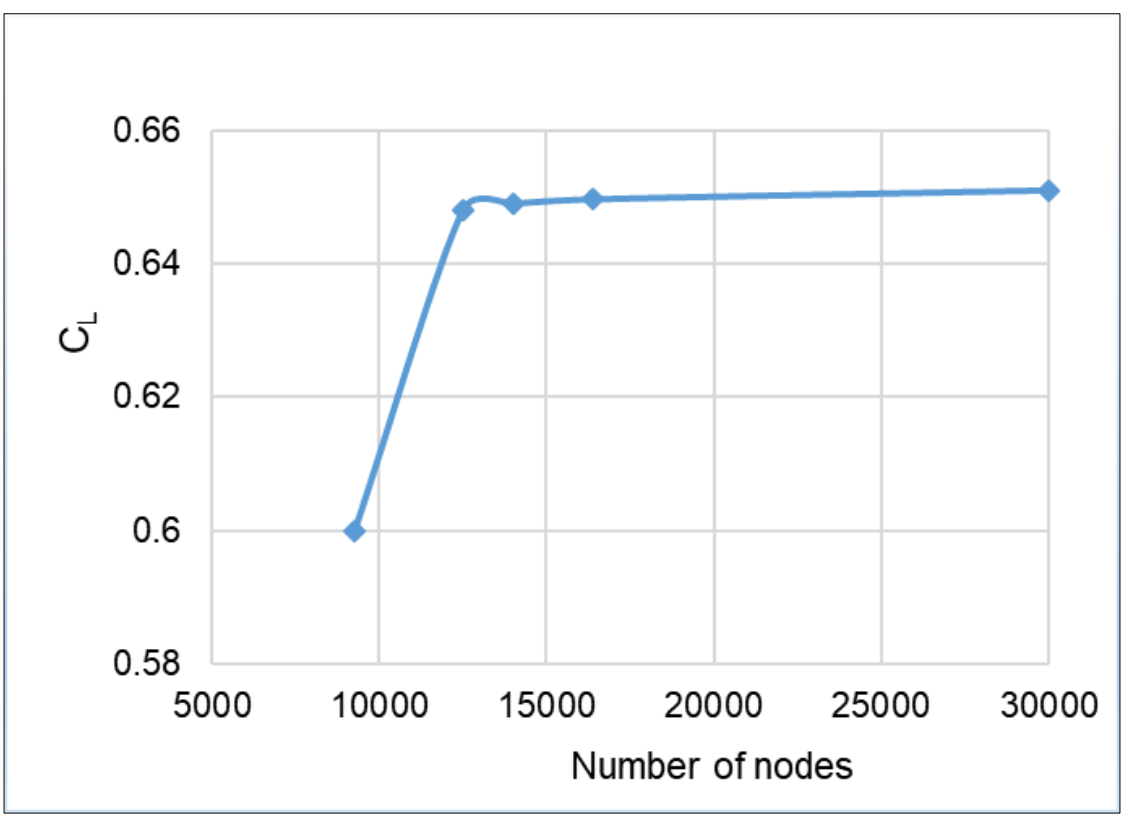

Fig. 3. Grid independence analysis 


\section{Wall Correction Factor Computation Procedure}

In the beginning of the study the CFD setup is validated by comparison of free stream case (large domain of 24C) with experimental data from two different sources [24, 25]. The mesh is refined until an acceptable error lift coefficient is within $6 \%$.

Figure 4 shows comparison of free stream case with experimental results. The CFD results are in close agreement with data from reference [25]. It is worth to note that considerable difference appears between experimental data from NACA TM4074 [25] and Abbott at higher angles of attack [21].

This CFD setup is applied to the studied computational domains. For each domain flow filed is solved for a set of angles of attack from 0 to 10 degrees. A lift curve slope is then calculated for each domain. A correction factor $K_{a}$ defined as the ratio of lift curve slope calculated for the computational domain height $h$ to the lift curve slope of free stream case. It is called wind tunnel wall correction factor. The objective of these simulation scenarios is to calculate this correction factor and compare it to the published data.

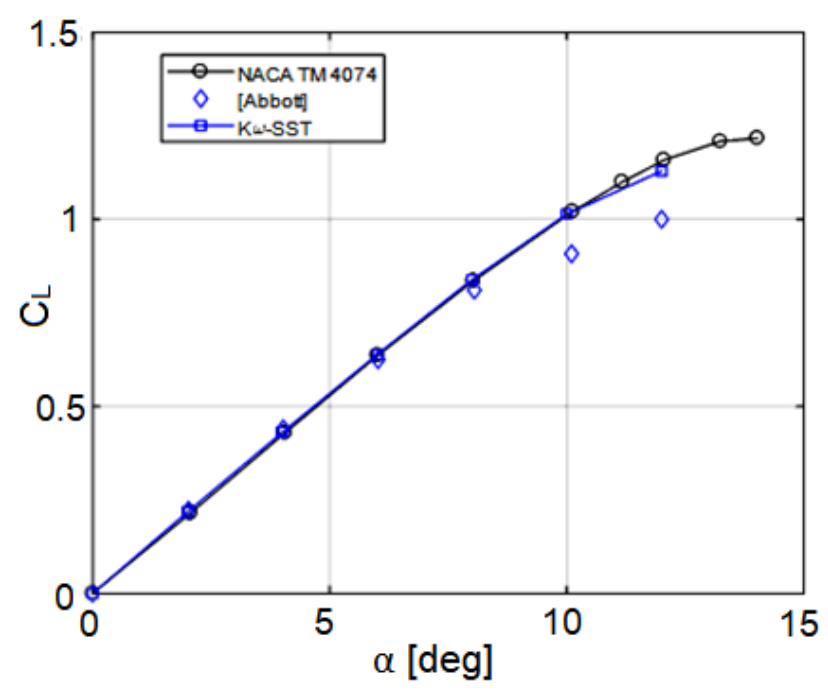

Fig. 4. Comparison of free stream case with experimental data

\section{Results and Discussion}

In order to study the wind tunnel height effects, a separate domain size and associated grid is prepared for each domain height $\mathrm{h}$ from $2 \mathrm{C}$ to $7 \mathrm{C}$. In addition to these cases a fee stream case with domain size of $24 \mathrm{C}$ in all directions is also prepared, where $C$ is the airfoil chord.

The free stream domain dimensions are chosen far from the airfoil such that there are no variations in pressure at the domain upper and lower sides. When the domain height is small the walls are close to the airfoil and it creates together with the airfoil upper and lower surfaces an area change (nozzle like effect) which in turn increases velocity over the airfoil and alters the pressure distribution resulting in an increased lift and drag compared to free stream case. As the domain size increases the walls move away from the airfoil upper and lower surfaces and the wall effect diminishes. Therefore, the flow becomes closer to free stream case.

Figures 5 and 6 show the results for the smallest domain size $h=2 \mathrm{C}$ as functions of angle of attack compared with free stream case. The deference between the two curves in each figure is function of the angle of attack. At zero angle of attack the lift is zero and the two curves coincide. This is 
attributed to the airfoil symmetry causing pressure changes from upper and lower surfaces to cancel. When angle of attack increases and in presence of close domain sides (walls) the flow over the upper and lower airfoil surfaces becomes different causing additional lift.

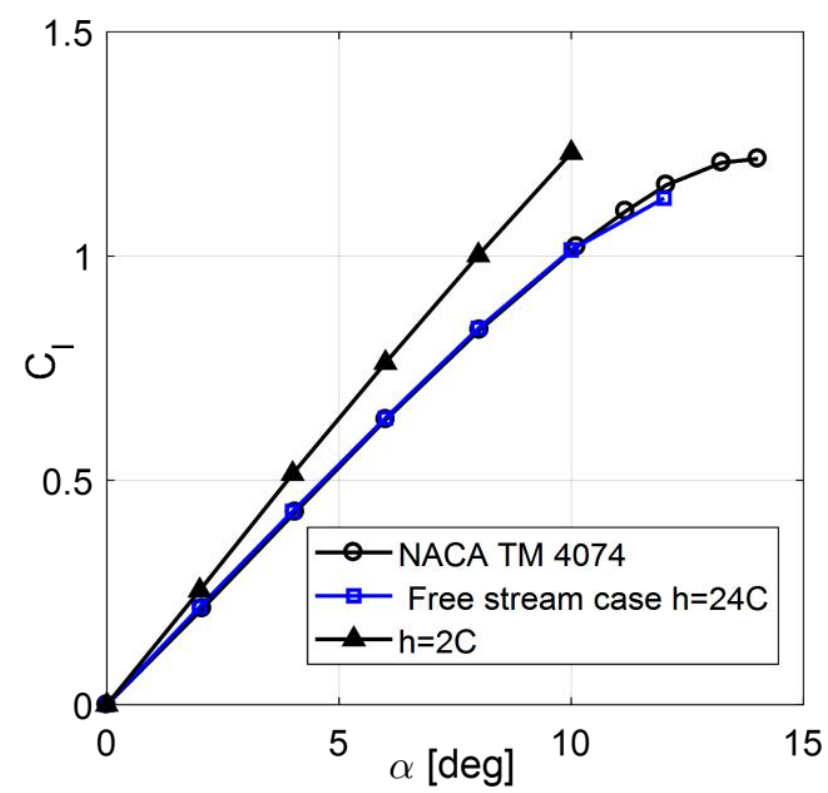

Fig. 5. Effect of wind tunnel wall height on lift coefficient at $\mathrm{h}=2 \mathrm{C}$

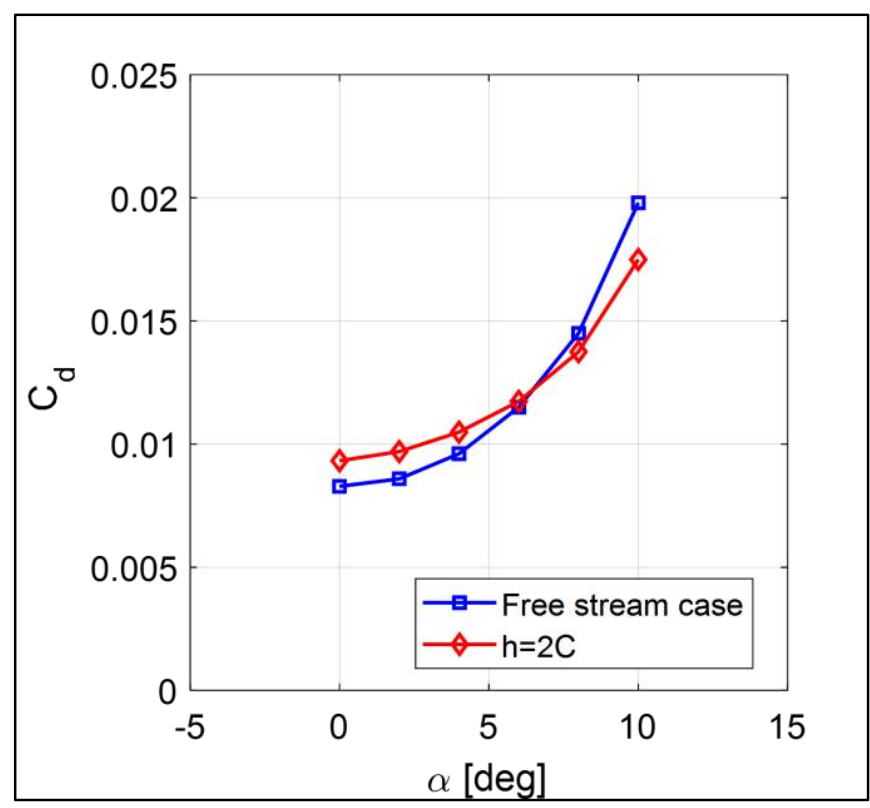

Fig. 6. Effect of wind tunnel wall height on drag coefficient at $h=2 C$

Figure 7 shows lift versus angle of attack for different wind tunnel wall heights compared to the free stream and data from reference [25]. Free stream case, which represents far wind tunnel walls, is good agreement with experimental data. For the same angle of attach, as wind tunnel walls become closer, the airfoil lift coefficient increases. The smallest wind tunnel wall height, $h=2 \mathrm{C}$, shows the maximum wall effect on the lift coefficient. It could be seen that, as wind tunnel wall height decreases lift curve slope increases. Therefore, a wind tunnel lift slope correction is necessary. 


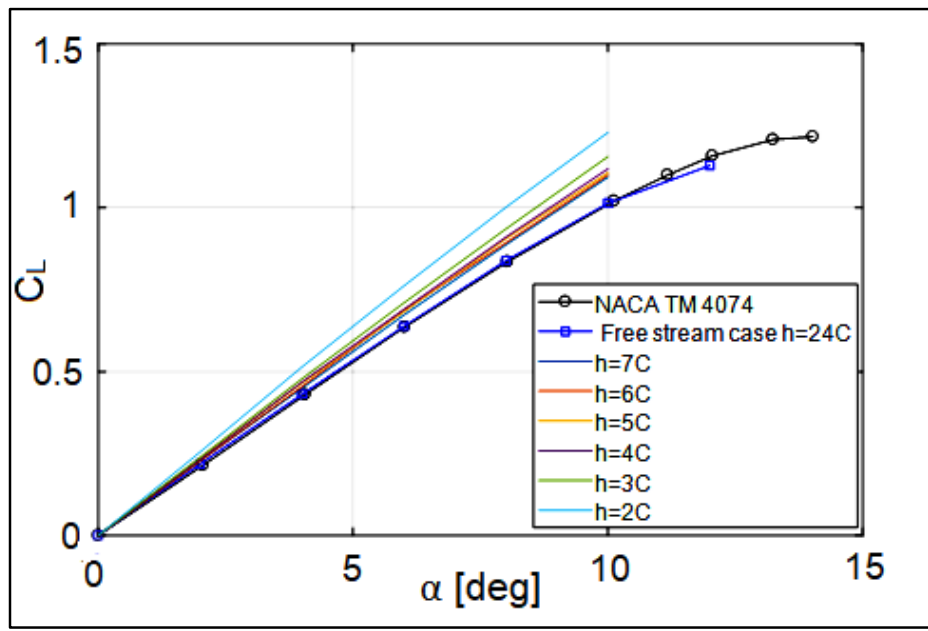

Fig. 7. Effect of Wind Tunnel Wall height $h$ on lift coefficient

The lift curve slope correction factor, $K_{a}$, at difference wind tunnel heights is shown in Table 2 . The numerical values of $C_{L \alpha}$ and the correction factor for each case are also shown. Figure 8 shows a comparison of the numerical lift curve correction factor obtained by current numerical procedure with data published in Ref. [25]. The comparison shows a close agreement with experimental data with consistent under estimation.

Table 2

Lift curve correction factor at difference wind tunnel heights

\begin{tabular}{|c|c|c|c|c|c|c|}
\hline & $h=2 C$ & $h=3 C$ & $h=4 C$ & $h=5 C$ & $h=6 C$ & $h=7 C$ \\
\hline$C_{L} \alpha$ (free stream) & 0.1066 & 0.1066 & 0.1066 & 0.1066 & 0.1066 & 0.1066 \\
\hline$C_{L \alpha(K \omega ~ S S T .)}$ & 0.12302 & 0.11562 & 0.1119 & 0.11073 & 0.11 & 0.1094 \\
\hline$K_{\mathrm{a}}$ Current study & 0.866526 & 0.921986 & 0.952636 & 0.962702 & 0.969091 & 0.974406 \\
\hline$K_{\mathrm{a}}[25]$ & - & 0.9419 & 0.9667 & 0.9782 & 0.9846 & - \\
\hline
\end{tabular}

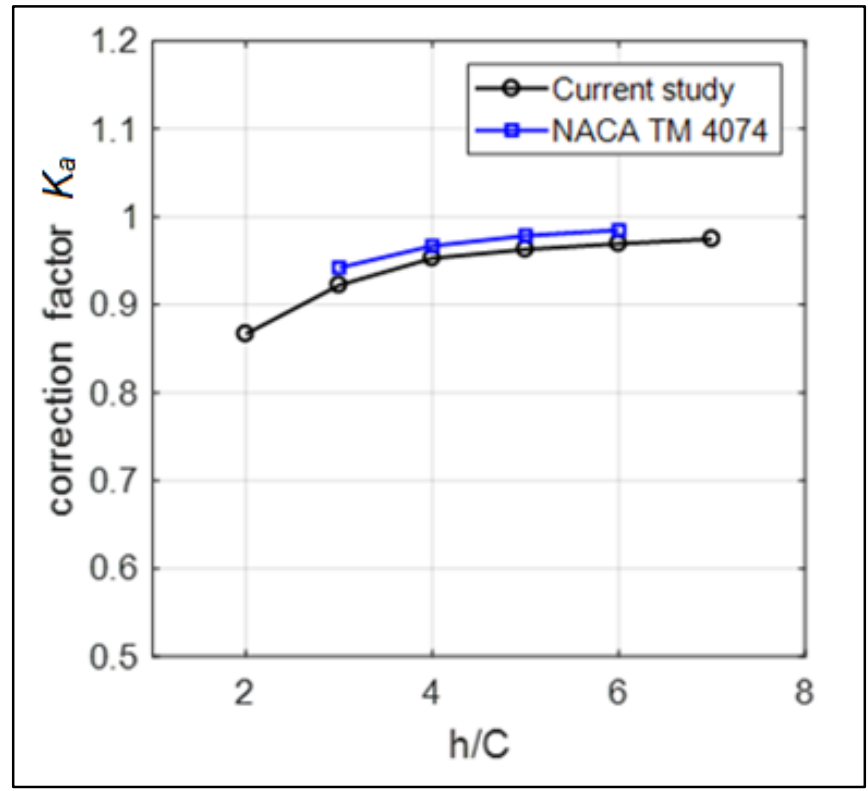

Fig. 8. Numerical Lift curve slop correction for free stream and wind tunnel wall effect for a NACA 0012 


\section{Conclusions}

Wall effects on an airfoil at different angles of attack have been computationally studied. Twodimensional flow over a NACA 0012 airfoil for different computational domain heights and at operating Reynolds number of $6 \times 10^{6}$ have been simulated by using the Ansys Fluent software. $k-\omega$ shear stress transport (SST-K $\omega$ ) turbulence model has been used for this simulation. The simulation results have been validated by comparison with experimental data from Ladson NASA TM 4074 [25] and Abbott experimental results [24]. Effects of effect of wind tunnel wall height $h$ on lift and drag coefficients are investigated. The lift curve slope correction factor at difference wind tunnel heights has been calculated and compared with the experimental data. The comparison shows a close agreement with published experimental data with consistent under estimation.

\section{Acknowledgement}

The authors would like to acknowledge the Research Management Centre (RMC), Universiti Tun Hussein Onn Malaysia for the financial support under the RMC Research Fund (E15501).

\section{References}

[1] Tongqing, G. U. O., L. U. Daixiao, L. U. Zhiliang, Z. H. O. U. Di, L. Y. U. Binbin, and W. U. Jiangpeng. "CFD/CSD-based flutter prediction method for experimental models in a transonic wind tunnel with porous wall." Chinese Journal of Aeronautics (2020). https://doi.org/10.1016/j.cja.2020.05.014

[2] Pope, Alan, and John J. Harper. "Low Speed Wind Tunnel Testing, John Willy and Sons." New York (1966). https://www.wiley.com/en-gy/exportProduct/pdf/9780471557746

[3] Blackwell, Ben F., Louis V. Feltz, and Robert E. Sheldahl. Wind tunnel performance data for two-and three-bucket Savonius rotors. Albuquerque, New Mexico: Sandia Laboratories, 1977.

https://ui.adsabs.harvard.edu/abs/1978JEner...2..160S

[4] Alexander, A. J., and B. P. Holownia. "Wind tunnel tests on a Savonius rotor." Journal of Wind Engineering and Industrial Aerodynamics 3, no. 4 (1978): 343-351. https://doi.org/10.1016/0167-6105(78)90037-5

[5] Maskell, E. C. A theory of the blockage effects on bluff bodies and stalled wings in a closed wind tunnel. No. ARCR/M-3400. Aeronautical Research Council London (United Kingdom), 1963.

http://naca.central.cranfield.ac.uk/reports/arc/rm/3400.pdf

[6] Ross, Ian, and Aaron Altman. "Wind tunnel blockage corrections: Review and application to Savonius vertical-axis wind turbines." Journal of Wind Engineering and Industrial Aerodynamics 99, no. 5 (2011): 523-538. https://doi.org/10.1016/i.jweia.2011.02.002

[7] Chen, T. Y., and L. R. Liou. "Blockage corrections in wind tunnel tests of small horizontal-axis wind turbines." Experimental Thermal and Fluid Science 35, no. 3 (2011): 565-569. https://doi.org/10.1016/i.expthermflusci.2010.12.005

[8] Zaghi, S., R. Muscari, and A. Di Mascio. "Assessment of blockage effects in wind tunnel testing of wind turbines." Journal of Wind Engineering and Industrial Aerodynamics 154 (2016): 1-9.

https://doi.org/10.1016/i.jweia.2016.03.012.

[9] Niu, Jianping, Juanmian Lei, and Tianyu Lu. "Numerical research on the effect of variable droop leading-edge on oscillating NACA 0012 airfoil dynamic stall." Aerospace Science and Technology 72 (2018): 476-485. https://doi.org/10.1016/j.ast.2017.11.030

[10] Raveh, D. E., and E. H. Dowell. "Frequency lock-in phenomenon for oscillating airfoils in buffeting flows." Journal of Fluids and Structures 27, no. 1 (2011): 89-104. https://doi.org/10.1016/i.jfluidstructs.2010.10.001

[11] Gao, Chuanqiang, Weiwei Zhang, and Zhengyin Ye. "Reduction of transonic buffet onset for a wing with activated elasticity." Aerospace Science and Technology 77 (2018): 670-676. https://doi.org/10.1016/j.ast.2018.03.047

[12] Liu, Jian, Kunyu Luo, Haisheng Sun, Yong Huang, Zhitao Liu, and Zhixiang Xiao. "Dynamic response of vortex breakdown flows to a pitching double-delta wing." Aerospace Science and Technology 72 (2018): 564-577. https://doi.org/10.1016/i.ast.2017.10.008 
[13] Besem, Fanny M., Joshua D. Kamrass, Jeffrey P. Thomas, Deman Tang, and Robert E. Kielb. "Vortex-induced vibration and frequency lock-in of an airfoil at high angles of attack." Journal of Fluids Engineering 138, no. 1 (2016). https://doi.org/10.1115/1.4031134

[14] Tang, Deman, and Earl H. Dowell. "Experimental aerodynamic response for an oscillating airfoil in buffeting flow." AIAA journal 52, no. 6 (2014): 1170-1179. https://doi.org/10.2514/1.j052077

[15] Malavasi, Stefano, and Gianluca Blois. "Wall effects on the flow structure around a rectangular cylinder." Meccanica 47, no. 4 (2012): 805-815. https://doi.org/10.1007/s11012-009-9199-x

[16] Ota, Terukazu, Yasunori Okamoto, and Hiroyuki Yoshikawa. "A correction formula for wall effects on unsteady forces of two-dimensional bluff bodies." J. Fluids Eng (1994): 414-418. https://doi.org/10.1115/1.2910292

[17] Chen, Jerry M., and Yuan-Cheng Fang. "Strouhal numbers of inclined flat plates." Journal of wind engineering and industrial aerodynamics 61, no. 2-3 (1996): 99-112. https://doi.org/10.1016/0167-6105(96)00044-x

[18] Zhou, Tong, Earl Dowell, and Shun-shan Feng. "Computational investigation of wind tunnel wall effects on buffeting flow and lock-in for an airfoil at high angle of attack." Aerospace Science and Technology 95 (2019): 105492. https://doi.org/10.1016/i.ast.2019.105492

[19] Hakim, Muhammad Syahmi Abdul, Mastura Ab Wahid, Norazila Othman, Shabudin Mat, Shuhaimi Mansor, Md Nizam Dahalan, and Wan Khairuddin Wan Ali. "The effects of Reynolds number on flow separation of Naca Aerofoil." Journal of Advanced Research in Fluid Mechanics and Thermal Sciences 47, no. 1 (2018): 56-68. http://www.akademiabaru.com/doc/ARFMTSV47 N1 P56 68.pdf

[20] Elfaghi, A. M., W. Asrar, and A. A. Omar. "A High Order Compact-Flowfield Dependent Variation (HOC-FDV) Method for Inviscid Flows." International Journal for Computational Methods in Engineering Science and Mechanics 11, no. 5 (2010): 258-263. https://doi.org/10.1080/15502287.2010.501322

[21] Ali S. Bahr Ennil and Abdulhafid M. Elfaghi. "Numerical Simulation of Film Cooling Over Flat Plate." ARPN Journal of Engineering and Applied Sciences 10, no. 6 (2015): 2518-2522. http://www.arpnjournals.com/jeas/research_papers/rp_2015/jeas 0415 1789.pdf

[22] Elfaghi, Abdulhafid M., Waqar Asrar, and Ashraf A. Omar. "Comparison of high-order accurate schemes for solving the nonlinear viscous burgers Equation." Australian Journal of Basic and Applied Sciences 3, no. 3 (2009): 25362543.

http://www.ajbasweb.com/old/ajbas/2009/2536-2543.pdf

[23] Ashford, Gregory Allan. "An unstructured grid generation and adaptive solution technique for high Reynolds number compressible flows." PhD diss., 1996. http://hdl.handle.net/2027.42/129935

[24] Abbott, Ira H., and Albert E. Von Doenhoff. Theory of wing sections: including a summary of airfoil data. Courier Corporation, 2012.

[25] Ladson, Charles L. Effects of independent variation of Mach and Reynolds numbers on the low-speed aerodynamic characteristics of the NACA 0012 airfoil section. Vol. 4074. National Aeronautics and Space Administration, Scientific and Technical Information Division, 1988. 